\title{
Occupational exposure to carcinogens and risk of lung cancer: results from The Netherlands cohort study
}

\author{
A Jeanne $M$ van Loon, I Jmert Kant, Gerard M H Swaen, R Alexandra Goldbohm, \\ Anja M Kremer, Piet A van den Brandt
}

\begin{abstract}
Objectives-To investigate risk of lung cancers associated with common established carcinogenic occupational exposures (asbestos, paint dust, polycyclic aromatic hydrocarbons, and welding fumes) in a prospective cohort study among the general population, and to estimate the proportion of lung cancer cases attributable to these occupational exposures.
\end{abstract}

Methods-A prospective cohort study on diet, other lifestyle factors, job history, and cancer risk that started in 1986 in The Netherlands on 58279 men, aged 55-69 years. Based on information about job history obtained from a self administered questionnaire, case by case expert assessment was carried out to assign to each study subject a cumulative probability of occupational exposure for each carcinogenic exposure. For analysis, a casecohort approach was used, in which the person-years at risk were estimated from

University of Limburg, Department of Epidemiology, PO Box 616, $6200 \mathrm{MD}$ Maastricht, The Netherlands

A Jeanne $M$ van Loon

I J Kant

G M H Swaen

R A Goldbohm

P A van den Brandt

TNO-Nutrition and Food Research Institute, Department of Consumer Research and Epidemiology, PO Box 360, 3700 AJ Zeist, The Netherlands R A Goldbohm

TNO-Prevention and Health, Division Work and Health, PO Box 2215, 2301 CE Leiden, The Netherlands

A $M$ Kremer

Correspondence to: Dr A Jeanne $M$ van Loon, University of Limburg, Department of Epidemiology, PO Box 616 6200 MD Maastricht, The Netherlands. cancer in men is attributable to lifetime occupational exposure to asbestos.
(Occup Environ Med 1997;54:817-824)

Keywords: lung cancer; occupation; population attributable risk

Lung cancer is the main cause of cancer mortality and incidence among men in The Netherlands. In the period $1979-90,37.6 \%$ of all fatal cancers in men were diagnosed as lung cancer $^{1}$ and in the preceding decade this percentage was $35.9 \%{ }^{2}$ In $1991,35.5 \%$ of all incident cases of cancer diagnosed in the male Dutch population were lung cancer. ${ }^{3} \mathrm{~A}$ high proportion of these cases is attributable to past smoking habits. Doll and Peto ${ }^{4}$ have estimated that about $85 \%$ of the deaths from lung cancer are attributable to cigarette smoking. Also several chemicals to which workers can be exposed have been identified as agents that increase the risk of lung cancer. Therefore, we studied the association between occupational exposure to carcinogens and risk of lung cancer, after adjustment for smoking habits. The agents and occupations presenting an increased risk for lung cancer to be included in this study were based on the evaluations made by the International Agency for Research on Cancer (IARC). From the update presented by IARC in 1987 two agents asbestos and polycyclic aromatic hydrocarbons (PAHs) were identified to have sufficient evidence of carcinogenity for the human lung and to which a cross section of the general population was estimated to be often exposed. ${ }^{5}$ Also later IARC monographs were reviewed to see if any other relevant occupations or agents had subsequently been identified. Two occupations met these criteria - namely, painters ${ }^{6}$ and welders. ${ }^{7}$ For welders welding fumes are regarded as the relevant exposure. An IARC Working Group has concluded that there is sufficient evidence of carcinogenicity due to occupational exposure in painters, but not in paint manufacturers. ${ }^{6}$ It was concluded that the relevant exposure in the induction of lung cancer in painters is exposure to paint dust, which is emitted during the removal of old layers of paint and filler.

Therefore, we defined the exposure for painters relative to lung cancer as paint dust (which is always combined with exposure to solvents) instead of exposure to solvents (which is not always combined with exposure to paint dust). So, asbestos, PAHs, welding fumes, and paint dust were selected as the occupational 
risks of lung cancers to be evaluated. Maintenance painters are considered to be definitely exposed to paint dust. Spray painters or construction painters are not considered to be exposed to paint dust.

Doll and Peto have estimated the proportion of cases of lung cancer attributable to occupational exposures in men to be $15 \%$ Other estimates vary from $9.2 \%$ to $13 \%$." The population attributable risk (PAR) or aetiological fraction has been defined as the proportion of all cases in the target population attributable to a specific exposure. " The PARs cannot be estimated solely on the basis of cohort studies of exposed workers, because it is necessary to have information on the prevalence of exposure in the general population. The Netherlands cohort study on diet, lifestyle, job history, and cancer does provide this information for the general population.

Information from this study was used to investigate risk of lung cancers from the four occupational exposures already mentioned. As the intake of $\beta$-carotene, vitamin $C$, and retinol is also related to risk of lung cancer, ${ }^{1311}$ information about smoking habits and intake of vitamin $C, \beta$-carotene, and retinol was used to disentangle possible effects from occupational exposure and possible effects from lifestyle factors. Finally, the corrected rate ratios (RRs) for ever exposed men versus never exposed men were used to estimate the PAR of lung cancer due to occupational exposures.

\section{Materials and methods}

COHORT STUDY

The Netherlands cohort study (NLCS) is a prospective cohort study on diet, other lifestyle factors, sociodemographic characteristics, job history, and cancer risk, which started in 1986 among the general population in The Netherlands. $^{12}$ In September 1986340439 men and women aged 55-69 years were asked to fill in a self administered questionnaire on diet, various lifestyle variables, job history, and other risk factors for cancer (such as socioeconomic status, history of selective medical conditions, family history of cancer, reproductive history, and physical activity) The response rate was $36 \%$, resulting in a male cohort size of 58279 . In earlier studies the representativeness of the 58279 men has been investigated.' 2 Several factors such as demographic variables, smoking, and dietary habits were compared between the cohort and the Dutch general population. It was found for these variables that the cohort was fairly representative for the total Dutch population. Therefore it was concluded that the response rate had not adversely affected determinant distributions in the cohort under investigation.

To achieve a study population free from cancer, prevalent cases of cancer, except skin cancer, were excluded from the cohort at the time of cohort identification (baseline). Prevalent cases were identified by means of specific questions included in the self administered questionnaire.

Follow up for incidence of cancer has been established by periodic record linkage with a national pathology register (PALGA) and with all regional cancer registries in The Netherlands. ${ }^{15}$ Thus cancer cases were identified without any knowledge of the individual exposure status and information on occupational exposure was collected before any knowledge of the disease. This feature of the data collection process effectively eliminates any possibility of information bias.

For data analysis the case cohort approach was used in which cases are derived from the entire cohort, whereas the person-years at risk are estimated for a random sample of 1688 subjects (subcohort). After exclusion of self reported prevalent cancer cases, other than skin cancer, 1630 men remained in the subcohort. The main advantage of this study design is its efficiency as exposure assessment is restricted to the cases and subcohort subjects only.

After the baseline exposure measurement the subcohort has been followed up biennially for information on vital status. No subcohort members were lost to follow up. The cases of lung cancer were diagnosed in the period from September 1986 to December 1990. During 4.3 years of follow up 677 incident cases of lung cancer were detected in the total cohort of 58279 men. These 677 cases were all identified through PALGA or the regional cancer registries.

EXPOSURE ASSESSMENT

For the exposure assessment by experts information from the baseline questionnaire of the NLCS was used. This information can be best described as a lifetime self reported job history, containing data on job titles, names of the company, type of company, periods, and information about what was being produced at the department. As baseline measurements were collected in September 1986 lifetime job history extended up to that date.

The whole data processing and assessment of exposure probability was done without knowledge of the disease status (case or subcohort) of the subjects. Firstly a list of all jobs in The Netherlands was independently reviewed by an occupational hygienist (IJK) and an occupational epidemiologist (GS). In this first examination all jobs with no potential exposure to lung cancer carcinogens were excluded. Secondly, for a more refined exposure assessment the name of the company, type of company, period, and information about what was being produced in the department was used, as the probability of exposure to some carcinogens may differ between companies and between periods. Therefore, each job title, specified by period and company, was scored separately according to the probability of exposure to the four carcinogens: asbestos, paint dust, PAHs, and welding fumes (particularly stainless steel welding). Four exposure categories were defined: no exposure to the specific carcinogen, possible exposure (probability of exposure estimated to be $<30 \%$ ), probable exposure (probability of exposure 30\%-90\%), and nearly certain exposure (probability of exposure $>90 \%$ ). In a final review round all the 
jobs for which at least one of the two reviewers suspected relevant exposure were reevaluated and a definite probability of exposure was assigned to each of the job titles within the NLCS.

\section{MEASUREMENT OF OCCUPATIONAL EXPOSURES}

For a measurement of exposure a cumulative probability of exposure (CPE) was calculated, which combines information about the probability of exposure and the duration of possible exposure. Therefore a weight was assigned to each exposure category: no exposure, weight 0 ; possible exposure, weight 0.15 ; probable exposure, weight 0.6 ; and nearly certain exposure, weight 0.95 . Each weight corresponds to the midpoint of probability in each exposure category. The CPE was calculated by multiplication of the weight given to each exposure category by the number of years exposed. Subsequently, for each person all weighted exposures were summed up for each of the four carcinogens separately.

\section{DATA ANALYSIS}

In the subcohort 1316 of the 1630 men ( $81 \%$ ) had completed the self reported job history inventory, whereas 524 of the 677 cases $(77 \%)$ had done so. For these people the distribution of the CPE was compared between the cases and subcohort. The CPEs to asbestos, PAHs, or welding fumes were divided into four categories (no exposure and tertiles of exposure) and the CPE to paint dust was divided into three categories (no exposure and below and above the median exposure value). These categories were based on the distribution of CPEs in the subcohort. The associations between CPE to occupational carcinogens and covariates were also studied in the subcohort by comparing the prevalence of smoking and by comparing mean values of age, pack-years of smoking, and dietary intake of vitamin $\mathrm{C}$, $\beta$-carotene, and retinol between CPE categories. To study the association between CPE to carcinogens and risk of lung cancer, data were analysed according to the case-cohort approach $^{16}{ }^{17}$ with the GLIM statistical package. ${ }^{18}$ In the multivariate analyses, RRs and $95 \%$ confidence intervals (95\% CIs) of risk of lung cancer were computed for each of the different occupational exposures, after adjustment for age and after further adjustment for the other three occupational exposures. All these covariates were entered in the model as continuous variables. Additional adjustment was made for smoking habits (never smokers, ex-smokers, current smokers, and pack-years of cigarette smoking) and for dietary intake of vitamin $C, \beta$-carotene, and retinol (as continuous variables). Finally, the PAR was calculated, based on the corrected RRs for ever exposed versus never exposed people.

\section{Results}

Table 1 shows the distribution of the cumulative probability of exposure to each of the four carcinogens in the case and the subcohort group. Cases were more often exposed to
Table 1 Distribution of exposure categories in male lung cancer cases and subcohort:cumulative probability of exposure

\begin{tabular}{|c|c|c|c|c|}
\hline \multirow[b]{2}{*}{ Exposure } & \multicolumn{2}{|c|}{$\begin{array}{l}\text { Subcohort } \\
(n=1316)+\end{array}$} & \multicolumn{2}{|c|}{$\begin{array}{l}\text { Cases } \\
(n=524) t\end{array}$} \\
\hline & $n$ & $\%$ & $n$ & $\%$ \\
\hline \multicolumn{5}{|l|}{ Asbestos: } \\
\hline 0 (no exposure) & 1200 & 91.6 & 448 & 86.2 \\
\hline 1 Tertile (low) & 34 & 2.6 & 21 & 4.0 \\
\hline 2 Tertile & 38 & 2.9 & 18 & 3.5 \\
\hline 3 Tertile (high) & 38 & 2.9 & 33 & 6.3 \\
\hline \multicolumn{5}{|l|}{ Paint dust: } \\
\hline 0 (no exposure) & 1300 & 98.8 & 506 & 96.5 \\
\hline 1 low & 8 & 0.6 & 4 & 0.8 \\
\hline 2 high & 8 & 0.6 & 14 & 2.7 \\
\hline \multicolumn{5}{|l|}{ PAHs: } \\
\hline 0 (no exposure) & 1243 & 94.9 & 487 & 93.5 \\
\hline 1 Tertile (low) & 21 & 1.6 & 10 & 1.9 \\
\hline 2 Tertile & 23 & 1.8 & 12 & 2.3 \\
\hline 3 Tertile (high) & 23 & 1.8 & 12 & 2.3 \\
\hline \multicolumn{5}{|l|}{ Welding fumes: } \\
\hline 0 (no exposure) & 1169 & 89.4 & 457 & 87.9 \\
\hline 1 Tertile (low) & 46 & 3.5 & 17 & 3.3 \\
\hline 2 Tertile & 46 & 3.5 & 26 & 5.0 \\
\hline 3 Tertile (high) & 47 & 3.6 & 20 & 3.8 \\
\hline
\end{tabular}

*Product of probability (weights $0.15,0.6$, and 0.95 ) and duration (y) of exposure, approximately divided into tertiles or into two equal categories (paint dust).

†Numbers may not add up to 1316 or 524 due to missing values for duration of exposure.

asbestos and paint dust than subcohort members. No notable difference in CPE to PAHs or welding fumes was found between cases and subcohort members.

Table 2 shows the association between the CPE and covariates in the subcohort. Differences in mean age between ever exposed and never exposed people were small. The prevalence of smoking was lower in people who were ever exposed to asbestos, PAHs, or welding fumes, than in never exposed people, whereas the prevalence of smoking was higher among people who were ever exposed to paint dust. The mean number of pack-years (for current and ex-smokers) was higher in people who were ever exposed to one of the investigated carcinogens than in those who were never exposed. The mean dietary intake of vitamin $\mathrm{C}$ was higher in people who were ever exposed to asbestos and lower among people who were ever exposed to paint dust or PAHs than in never exposed men in the subcohort. The mean intake of $\beta$-carotene was also lower among people who were ever exposed to paint dust or PAHs and the mean intake of retinol was only lower in people who were ever exposed to paint dust. Finally, there was a correlation between exposure to asbestos, PAHs, and welding fumes, whereas there was no correlation between exposure to paint dust and exposure to asbestos, PAHs, or welding fumes.

Table 3 shows the results of the case-cohort analyses. After adjustment for age, there was a positive association between CPE to asbestos and risk of lung cancer (trend $P<0.01$ ). Men in the highest exposure category had a significantly higher risk of lung cancer than men with no occupational exposure to asbestos ( $R R$ $2.66 ; 95 \%$ CI 1.66 to 4.26 ). There was also a significant positive association between CPE to paint dust and risk of lung cancer (highest exposure/no exposure RR 3.60; 95\% CI 1.48 to 8.74; trend $P<0.01$ ). No significant association between CPE to PAHs and risk of lung 
Table 2 Association between possible confounders and probability of exposure in the subcohort

\begin{tabular}{|c|c|c|c|c|c|c|c|c|}
\hline \multirow[t]{2}{*}{ Probability of exposure } & \multicolumn{2}{|c|}{ Asbestos } & \multicolumn{2}{|c|}{ Paint dust } & \multicolumn{2}{|l|}{$P A H s$} & \multicolumn{2}{|c|}{ Welding fumes } \\
\hline & Never & Ever & Never & Ever & Never & Ever & Never & Ever \\
\hline Age (mean y) & 61.3 & 60.7 & 61.3 & 61.8 & 61.3 & 60.6 & 61.4 & 60.3 \\
\hline Current smokers (\%) & 42.4 & 35.3 & 41.5 & 62.5 & 42.2 & 35.6 & 42.6 & 35.4 \\
\hline Ex-smokers (\%) & 47.8 & 54.3 & 48.5 & 37.5 & 48.0 & 54.8 & 47.5 & 55.8 \\
\hline Pack-years $^{\star}($ mean $)$ & 21.9 & 23.4 & 22.0 & 24.3 & 21.8 & 27.4 & 22.0 & 22.8 \\
\hline \multicolumn{9}{|l|}{ Dietary intake of: } \\
\hline Vitamin C (mean, mg) & 99.0 & 101.6 & 99.3 & 96.3 & 99.6 & 93.0 & 99.2 & 99.8 \\
\hline$\beta$-carotene (mean, mg eq vit $\mathrm{A}$ ) & 0.41 & 0.41 & 0.41 & 0.34 & 0.41 & 0.38 & 0.41 & 0.40 \\
\hline Retinol (mean, mg eq vit A) & 0.62 & 0.63 & 0.62 & 0.55 & 0.62 & 0.63 & 0.62 & 0.63 \\
\hline \multicolumn{9}{|l|}{ Exposure to: } \\
\hline Asbestos (\% ever) & - & - & 8.9 & 0 & 5.5 & 65.8 & 1.9 & 63.9 \\
\hline Paint dust ( $\%$ ever $)$ & 1.3 & 0 & - & - & 1.2 & 1.4 & 1.4 & 0 \\
\hline PAHs ( $\%$ ever) & 2.1 & 41.4 & 5.5 & 6.3 & - & & 2.6 & 29.3 \\
\hline Welding fumes ( $\%$ ever) & 4.4 & 81.0 & 11.3 & 0 & 8.4 & 58.9 & & \\
\hline
\end{tabular}

*Only for current and ex-smokers

Table 3 Rate ratios for lung cancer according to occupational exposures in age adjusted and multivariate analysis

\begin{tabular}{|c|c|c|c|c|c|}
\hline Lifetime exposure index $t$ & $\begin{array}{l}\text { No of cases } \\
\text { in cohort }\end{array}$ & $\begin{array}{l}\text { Person- } \\
\text { years in } \\
\text { subcohort }\end{array}$ & $R R(95 \% C I) \ddagger$ & $R R(95 \% C I) \mathcal{S}$ & $R R(95 \% C I)$ \\
\hline \multicolumn{6}{|l|}{ Asbestos: } \\
\hline 0 (no exposure) & 448 & 5005 & $1^{\star}$ & $1^{\star}$ & $1^{\star}$ \\
\hline 1 Tertile (low) & 21 & 141 & $1.76(1.02$ to 3.03$)$ & $1.82(1.04$ to 3.17$)$ & $1.59(0.75$ to 3.34$)$ \\
\hline 2 Tertile & 18 & 163 & $1.26(0.71$ to 2.23$)$ & $1.29(0.73$ to 2.30$)$ & $0.96(0.42$ to 2.19$)$ \\
\hline 3 Tertile & 33 & 157 & $2.66(1.66$ to 4.26$)$ & $2.72(1.56$ to 4.75$)$ & 3.49 (1.69 to 7.18$)$ \\
\hline Test for trend & & & $23.16(<0.01)$ & $19.07(<0.01)$ & $12.72(<0.01)$ \\
\hline$\chi^{2}$ (P value $)$ & & & & & \\
\hline \multicolumn{6}{|l|}{ Paint dust: } \\
\hline 0 (no exposure) & 506 & 5425 & $1^{\star}$ & $1^{\star}$ & $1^{\star}$ \\
\hline 1 low & 4 & 33 & $1.46(0.43$ to 4.97$)$ & $1.53(0.45$ to 5.21$)$ & $2.29(0.61$ to 8.63$)$ \\
\hline 2 high & 14 & 34 & $3.60(1.48$ to 8.74$)$ & $3.74(1.53$ to 9.11$)$ & $2.48(0.88$ to 6.97$)$ \\
\hline $\begin{array}{l}\text { Test for trend } \\
\alpha^{2}(\mathrm{P} \text { value })\end{array}$ & & & $15.58(<0.01)$ & $16.48(<0.01)$ & $7.67(<0.01)$ \\
\hline \multicolumn{6}{|l|}{ PAHs: } \\
\hline 0 (no exposure) & 487 & 5196 & $1^{\star}$ & $1^{\star}$ & $1^{\star}$ \\
\hline 1 Tertile (low) & 10 & 86 & $1.44(0.67$ to 3.09$)$ & $1.32(0.60$ to 2.89$)$ & $0.53(0.13$ to 2.14$)$ \\
\hline 2 Tertile & 12 & 96 & $1.61(0.78$ to 3.34$)$ & $1.09(0.49$ to 2.40$)$ & $0.83(0.32$ to 2.20$)$ \\
\hline 3 Tertile (high) & 12 & 92 & $1.35(0.66$ to 2.76$)$ & $0.63(0.25$ to 1.58$)$ & $0.28(0.09$ to 0.89$)$ \\
\hline Test for trend & & & $3.20(0.07)$ & $0.56(0.45)$ & $9.05(<0.01)$ \\
\hline$\chi^{2}$ (P value) & & & & & \\
\hline \multicolumn{6}{|l|}{ Welding fumes: } \\
\hline 0 (no exposure) & 457 & 4884 & $1^{\star}$ & $1^{\star}$ & $1^{\star}$ \\
\hline 1 Tertile (low) & 17 & 191 & $1.06(0.60$ to 1.89$)$ & $0.98(0.55$ to 1.76$)$ & $0.71(0.31$ to 1.60$)$ \\
\hline 2 Tertile & 26 & 192 & $1.73(1.05$ to 2.85$)$ & $1.16(0.63$ to 2.11$)$ & $1.49(0.72$ to 3.07$)$ \\
\hline 3 Tertile (high) & 20 & 191 & $1.26(0.73$ to 2.18$)$ & $1.02(0.56$ to 1.85$)$ & $1.01(0.49$ to 2.06$)$ \\
\hline Test for trend & & & $4.49(0.03)$ & $0.09(0.77)$ & $0.10(0.75)$ \\
\hline$\chi^{2}$ (P value $)$ & & & & & \\
\hline
\end{tabular}

^Reference category.

†Product of probability (weights $0.15,0.6$ and 0.95 ) $\times$ duration (years) of exposure, approximately divided into tertiles or into two categories (paint dust).

†Adjusted for age.

§Adjusted for age and other occupational exposures. If information on occupational exposure was lacking for a study subject, that person was excluded from the analysis.

IAdjusted for age, other occupational exposures, smoking (never/ex/current and pack-years), and intake of vitamin C, $\beta$-carotene, and retinol. If information on any variable for which the adjustments were made was lacking, that person was excluded from the analysis

cancer was found (trend $\mathrm{P}=0.07$ ), but the RRs for the three exposure categories (compared with non-exposed) were all above unity. The risk estimate for the CPE to welding fumes was only significantly different from unity in the middle tertile (RR $1.73,95 \%$ CI 1.05 to 2.85 ). Nevertheless, the trend test was also significant (trend $\mathrm{P}=0.03$ ).

After adjustment for age and for each of the other occupational exposures, the relative rates of PAHs and welding fumes were greatly diminished. The relative rates of exposure to asbestos and paint dust changed only marginally after adjustment and remained significant (table 3).

After additional adjustment for smoking habits and intake of vitamin $C, \beta$-carotene, and retinol, there was still a significant positive association between the cumulative probability of exposure to asbestos and risk of lung cancer (highest exposure/no exposure RR 3.49; 95\% CI 1.69 to 7.18 ; trend $\mathrm{P}<0.01$ ). There was also a positive association between CPE to paint dust and risk of lung cancer (highest exposure/no exposure RR 2.48; 95\% CI 0.88 to 6.97 ; trend $\mathrm{P}<0.01$ ), but part of the higher age adjusted risk among men in the highest paint dust exposure category seemed to be explained by smoking and intake of vitamin $C$, $\beta$-carotene, and retinol. The cumulative probability of exposure to PAHs became inversely associated with risk of lung cancer after additional adjustment for smoking and intake of vitamin $C, \beta$-carotene, and retinol (highest exposure/no exposure RR $0.28 ; 95 \%$ CI 0.09 to 0.89 ; trend $\mathrm{P}<0.01$ ). The association 
between the CPE to welding fumes and risk of lung cancer did not substantially change after additional adjustment.

Calculation of the PAR is based on the RRs for ever exposed versus never exposed people, adjusted for age, other exposures (never or ever), smoking, and intake of vitamin $C$, $\beta$-carotene, and retinol (table 4). Because we did not expect a protective effect of exposure to carcinogens, only $R R s>1$ were used to calculate the PAR - namely, for asbestos and paint dust. The PAR for exposure to asbestos was $11.6 \%$ and the PAR for exposure to paint dust was $1.7 \%$.

It is concluded that a substantial proportion (about $11.6 \%$ ) of all male lung cancer cases in the general Dutch population is attributable to lifetime occupational exposure to asbestos.

\section{Discussion}

We have found a positive association between the cumulative probability of exposure to asbestos, paint dust, and welding fumes and risk of lung cancer among men in the general population of The Netherlands. There was no association between the cumulative probability of exposure to PAHs and risk of lung cancer. The positive association between exposure to welding fumes and risk of lung cancer disappeared after additional adjustment for exposure to asbestos, paint dust, and PAHs, whereas the positive associations between asbestos or paint dust and risk of lung cancer remained after additional adjustment for the other exposures. Differences in smoking habits and intake of vitamin $C, \beta$-carotene, and retinol could not explain the positive association between exposure to asbestos or paint dust and risk of lung cancer, although the RRs for exposure to paint dust became smaller after adjustment for these lifestyle factors. The PAR for exposure to asbestos was $11.6 \%$ and the PAR for exposure to paint dust was $1.7 \%$.

The significant positive association between exposure to asbestos and risk of lung cancer is comparable with results from other studies. In most studies, exposure to asbestos is measured by job title, job history, or job exposure matrix and this information is either categorised as exposed versus non-exposed, ${ }^{19}$ as no exposure, possible exposure, and definite exposure ${ }^{20}{ }^{21}$ or by means of a lifetime exposure index. ${ }^{22}$ In all these studies a significantly positive association

Table 4 Rate ratios and population attributable risks for occupational exposures (non-exposed $v$ ever exposed)

\begin{tabular}{lllc}
\hline $\begin{array}{l}\text { Occupational } \\
\text { exposures }\end{array}$ & $\begin{array}{l}\text { Proportion of ever exposed } \\
\text { subcohort members }\end{array}$ & $R R(95 \%$ CI) & PARt \\
\hline Asbestos & 0.088 & $2.49(1.31$ to 4.75$)$ & 11.6 \\
Paint dust & 0.012 & $2.46(1.08$ to 5.60$)$ & 1.7 \\
PAHs & 0.055 & $0.53(0.26$ to 1.07$)$ & \\
Welding fumes & 0.112 & $0.86(0.46$ to 1.58$)$ & \\
\hline
\end{tabular}

*The proportion of ever exposed subcohort members is based on information about the probability of exposure. Information about duration of exposure is not included.

†After adjustment for age, other occupational exposures (never/ever), smoking (never/ex/current and pack-years of cigarette smoking), and intake of vitamin $C, \beta$-carotene, and retinol, the following formula was used to calculate the PAR: ${ }^{45}$

$\underline{p_{0}(R R-1)}$

$\frac{p_{0}(R R-1)}{p_{0}(R R-1)+1}$

where $p_{0}$ is the fraction of exposed subjects in the subcohort was found after adjustment for smoking habits, with relative risk estimates varying from $2.0^{21}$ to 4.1..$^{22}$ In one case-control study ${ }^{24}$ information about concentrations of asbestos fibre was available and the authors reported a significantly positive association between fibre count and risk of lung cancer. Only one study reported a non-significant positive association between cumulative exposure to asbestos and risk of lung cancer. ${ }^{25}$

In most studies on the risk of lung cancer in painters, no significantly increased risk was reported, ${ }^{25-28}$ although in all studies the odds ratios were above one. In our study attention was mainly focused on exposure to paint dust instead of exposure to organic solvents and dye products. This may explain the difference between our findings and the results from other studies. Nevertheless, one study on the risk of lung cancer in painters from the Scandinavian countries ${ }^{29}$ reported significantly higher risk of lung cancers for painters and lacquerers, with risk estimates varying from 1.3 to 1.4 .

Studies on PAHs and risk of lung cancer show varying results, ${ }^{22} 30$ probably due to differences in study population. In a cohort study among men who worked for at least one year in a manual job in a large aluminum production factory in Quebec, ${ }^{30}$ a significant positive association was found between exposure to benzo-a-pyrene (an indicator for PAHs in general) and lung cancer mortality. In a casecontrol study in Germany ${ }^{22}$ no significant association was found between exposure to PAHs and incidence of lung cancer, although in this study certain occupations which are associated with exposure to PAHs (metal producing and processing workers and road construction workers) showed significantly increased odds ratios. Finally, in a Norwegian cohort study of workers in the aluminum industry, ${ }^{31}$ it was suggested that the cases could have resulted from exposure to asbestos, rather than from exposure to PAHs. This is partly comparable with our results; the nonsignificantly increased risk of lung cancer among men exposed to PAHs disappeared after additional adjustment for exposure to asbestos.

In a review on cancer related to nickel in welders, Langård ${ }^{32}$ concluded that there was evidence of excess incidence of and mortality from lung cancer in welders with long term welding experience. There was also evidence that stainless steel welders had a slightly higher risk of lung cancer than did mild steel welders. However, exposure to asbestos and smoking are generally major confounders. In a metaanalysis about exposure to stainless steel welding fumes and risk of lung cancer ${ }^{33}$ a significant positive association was reported, after adjustment for smoking habits and exposure to asbestos. Only investigations taking smoking and exposure to asbestos into account were included in the meta-analysis, but in two of the five included studies, smoking and exposure to asbestos were based only on assumption. One objective of a case-control study on risk of lung cancer and welding in Germany ${ }^{34}$ was to assess confounding by exposure to asbestos in what was thought to be a risk associated with 
welding. The authors concluded that some, if not all, of the excess risk of welders may be due to exposure to asbestos, which is compatible with our results. Nevertheless, some types of welding processes in the German study still reached borderline significance after adjustment for exposure to asbestos.

In our study the adjusted relative risks for ever exposed versus never exposed people were used to calculate the PAR due to occupational carcinogens, which was estimated at $11.6 \%$ for exposure to asbestos and $1.7 \%$ for exposure to paint dust. The actual proportion due to occupational exposure may be higher as the occupational exposures under investigation were restricted to four common exposures. Other occupational exposures, such as exposure to certain heavy metals and bischloromethylether, were not included, because there was not sufficient evidence for carcinogenity for the human lung or exposure was not estimated to occur often in the general population. Unlike the relative risk, the PAR depends not only on the strength of the causal relation but also on the prevalence of the risk factors, giving more importance to common moderately hazardous factors than to rare but strong risk factors. Therefore, the contribution of rare exposures to the proportion of lung cancers in men attributable to occupational exposures is considered to be small. Simonato et a $\mathrm{l}^{35}$ investigated the attributable risk of occupational exposure from studies in which adjustment was made for smoking. They included 16 casecontrol studies and found a wide variability of attributable risk estimates. When a list of recognised carcinogenic exposures was used for the selection of relevant occupations, the estimates varied between $2.4 \%$ and $40 \%$. None of the studies were nationwide and consequently no attributable risks could be computed for the general population.

In our study the attributable risk of occupational exposure to asbestos in the past is $11.6 \%$. Other estimates vary from $6 \%$ in the west of Scotland including Glasgow ${ }^{36}$ and $14 \%$ in north eastern Italy (Trieste) for definite exposure to asbestos, and $20 \%$ for definite and possible exposure to asbestos, ${ }^{21} 16 \%$ in Göteborg, Sweden ${ }^{25}$ and $19 \%$ in Helsinki, Finland. ${ }^{24}$ These differences may be due to differences in exposure assessment but it is more likely that differences in levels of exposure in the study areas, partly due to the degree of industrialisation, may lead to these differences in attributable risk. In our study $8.8 \%$ of the subcohort was ever exposed to asbestos, whereas the number of exposed controls in the other studies varied from $17 \%{ }^{24}$ to $37 \% .^{25}$ These percentages are difficult to interpret because of differences in the definition of non-exposure.

Our cohort study has been performed in a large sample of the general population aged 55-69 years at baseline. The follow up period of 4.3 years resulted in 677 men with lung cancer. Job histories were available for 524 cases only. This number is considered to be sufficient, because in general about 400 cases are needed to detect relevant associations. ${ }^{37}$ The follow up of person-years was $100 \%$ complete and the completeness of cancer follow up was also very high, indicating that selection bias due to loss to follow up is unlikely. The study population originated from 204 municipalities throughout the country. Although the response rate was low (36\%), data on demographic variables, smoking, and dietary habits indicated that the response had not adversely affected determinant distributions in the present cohort. ${ }^{12}$ Even if the cohort would not have been representative for the total Dutch male population, the calculated RRs should not have been affected under the assumption that the subcohort and the case group were derived from the same subpopulation.

As the PAR is a combination of RRs and the proportion of ever exposed people the calculated PAR will be affected by nonrepresentativeness of the cohort. For example, if the cohort contains a smaller proportion of exposed people than the general population the calculated PAR will be an underestimation of the true PAR. Earlier studies of the cohort indicate that the distribution of educational level in the cohort is different from that in the general Dutch population. Subjects with high levels of education and those with low levels seem to be overrepresented. This may have led to a small overestimation of the PAR. The number of men aged 55-64 years with a high level of education (higher vocational or university) is higher in the subcohort (18\%) than in men with the same age in the Dutch population $(14 \%) .{ }^{38}$ However, the number of men with primary school or lower vocational education was also higher in the subcohort than in the general population $(48 \% v 37 \%)$. Therefore, the exposure to occupational carcinogens may be higher in the cohort and consequently, the actual PAR of the occupational carcinogens may be lower.

The quality of the exposure assessment strongly affects the outcome of the risk estimate $^{39}$ and ideally includes both intensity and duration of the occupational exposure for each specific study subject. However, in large population based studies it is almost impossible to obtain this quantitative information. Moreover, in this type of study the range of jobs with potential exposures is large and within given jobs there is a great possible variation of exposures. This makes it even more difficult to identify a clear link between jobs and exposures, compared with industry based studies. ${ }^{40}$ In our study the occupational history of the study subjects was obtained through questionnaires, which did not allow an estimation of the actual exposure concentrations that were experienced in the past. The best estimate was a retrospective exposure assessment in terms of probability of exposure. In general this can be obtained through a job exposure matrix (JEM) or a case by case expert assessment, as was used in this study. The main advantage of this method-compared with a JEM-is that all the available information (job title, type and name of the company, period) is used for the exposure assessment. ${ }^{40}$ Moreover, a JEM may produce greater non-differential misclassification than exposure assessment by experts ${ }^{404}$ 
because information returned by a JEM is mistakenly taken to relate to individual exposure. ${ }^{41}$ However, a JEM will be more reliable, as it will produce the same exposure information for identical basic data. ${ }^{41} \mathrm{~A}$ disadvantage of exposure assessment by experts is the learning phenomenon, because there is no fixed definition of the criteria which are used for the exposure assessment. However, by including a final review round for re-evaluation of all the jobs for which at least one of the two reviewers suspected relevant exposure this phenomenon was minimised. In this final review round a definitive probability of exposure was assigned to each job title.

In case by case expert assessments different measures for exposures are applied. The highest probability of exposure once experienced is often used ${ }^{42}$ and could be directly obtained from our exposure assessment. However, this measure discards the effect of duration of exposure which seemed to be essential in evaluation of exposures to carcinogenic agents. ${ }^{3943}{ }^{44}$ To incorporate the effect of duration of exposure we calculated a cumulative probability of exposure for the four carcinogens separately. We also used the highest probability of exposure as the measure of exposure instead of cumulative probability of exposure, which yielded similar results (data not shown).

In most studies on occupational exposure and lung cancer, smoking had no strong confounding effect on this association. ${ }^{10192021}$ This is comparable with our findings that adjustment for smoking did not substantially change the association between exposure to asbestos and risk of lung cancer. We found no other studies in which adjustment was also made for the intake of vitamin $C, \beta$-carotene, and retinol. We also found no studies on risk of lung cancer in painters in which adjustment was made for lifestyle variables. However, it is possible that exposure to paint dust may promote the effect of carcinogens in tobacco smoke. ${ }^{20}$ In that case smoking should be considered as an effect modifier instead of a confounding factor. Unfortunately, because of the few non-smokers among the male cases of lung cancer, it is not possible to compare the risks associated with exposure between nonsmokers and smokers. The unexpected results for PAH after adjustment for smoking and dietary intake of vitamin $C, \beta$-carotene, and retinol may be a chance finding. Further research on this subject will be possible after a longer follow up period. As well as the possible interaction between occupational exposure and lifestyle factors, there may be interaction between different occupational exposures.

We thank the participants in this study, the regional cancer registries (IKA, IKL, IKMN, IKN, IKO, IKR, IKST, IKW, IKZ) PALGA for providing incidence data, $E$ Dorant, $S$ van de Crommert, $H$ Brants, P Florax, J Nelissen, and W van Dijk for assistance in the cohort study, and $S$ van den Heuvel from the TNO PG institute for coding the questions about occupation. The NLCS was financially supported by the Dutch Cancer Society.

1 Centraal Bureau voor de Statistiek. Atlas van de kankersterfie in Nederland 1979-90. Den Haag: SDU Uitgeverij, 1992.

Centraal Bureau voor de Statistiek. Atlas van de kankersterft in Nederland 1969-78. Den Haag: Staatsuitgeverij, 1980. Netherlands Cancer Registry. Incidence of cancer in the NethNetherlands Cancer Registry.
erlands. Utrecht: NCR, 1991 .
4 Doll $R$, Peto $R$. The causes of cancer. Oxford: Oxford University Press, 1981 .

5 International Agency for Research on Cancer. Overall evaluations of carcinogenicity: an updating of IARC Monographs, vol 1 to 42. Lyon: IARC, 1987. (Suppl 7.)

6 International Agency for Research on Cancer. Some organic solvents resin monomers and related compounds, pigments and occupational exposure to paint manufacture and painting. Vol 47. Lyon: IARC, 1989.

7 International Agency for Research on Cancer. Chromium, nickel, and welding. Vol 49. Lyon: IARC, 1990.

8 Morabia A, Markowitz S, Garibaldi K, Wynder EL. Lung cancer and occupation: results of a multicentre casecancer and occupation: results of a multi

9 Higginson J, Muir CS. Proportion of cancers due to occupation. Prev Med 1980;9:180-8.

10 Schoenberg JB, Stemhagen A, Mason TJ, Patterson J, Bill J, Altman $R$. Occupation and lung cancer risk among New Jersey white males. $\mathcal{F}$ Natl Cancer Inst 1987;79:13-21.

11 Schlesselman JJ. Case-control studies, design, conduct, analysis. New York: Oxford University Press, 1982.

12 Van den Brandt PA, Goldbohm RA, Van 't Veer P, Volovics A, Hermus RJJ, Sturmans F. A large-scale prospective cohort study on diet and cancer in the Netherlands. $\mathcal{F}$ Clin Epidemiol 1990;43:285-95.

13 Block G. Vitamin C and cancer prevention: the epidemiologic evidence. Am $\mathcal{F}$ Clin Nutr 1991;53:270s-82s.

14 Graham S. Epidemiology of retinoids and cancer. $\mathcal{F}$ Natl Cancer Inst 1984;73:1423-8.

15 Van den Brandt PA, Schouten LJ, Goldbohm RA, Dorant E, Hunen PMH. Development of a record linkage protocol for use in the Dutch cancer registry for epidemiological research. Int $\mathcal{F}$ Epidemiol 1990;19:553-8.

16 Self SG, Prentice RL. Asymptotic distribution theory and efficiency results for case-cohort studies. Annals of Statistics 1988;16:64-81

17 Van den Brandt PA, Veer van 't P, Goldbohm RA, Dorant E, Volovics A, Hermus RJJ, Sturmans F. A prospective cohort study on dietary fat and the risk of postmenopausal breast cancer. Cancer Res 1993;53:75-82.

18 Baker RJ. GLIM 3.77. Reference manual. Oxford: Numerical Algorithms Group, 1985.

19 Martischnig KM, Newell DJ, Barnsley WC, Cowan WK, Feinmann EL, Oliver E. Unsuspected exposure to asbestos and bronchogenic carcinoma. BMF 1977;1:746-9.

20 Kjuus H, Skjaerven R, Langård S, Lien JT, Aamodt T. A case-referent study of lung cancer, occupational exposures and smoking - I. Comparison of title-based and exposurebased occupational information. Scand $f$ Work Environ Health 1986;12:193-202.

21 Bovenzi M, Stanta G, Antiga G, Peruzzo P, Cavallieri F. Occupational exposure and lung cancer risk in a coastal area of northeastern Italy. Int Arch Occup Environ Health 1993;65:35-41.

22 Jöckel K-H, Ahrens W, Wichmann H-E, Becher $\mathrm{H}$, Bolm-Audorff U, Jahn I, et al. Occupational and environmental hazards associated with lung cancer. Int $\mathcal{f}$ Epidemiol 1992;21:202-13.

23 Ahrens W, Jöckel K-H, Brochard P, Bolm-Audorff U, Grossgarten $\mathrm{K}$, Iwatsubo $\mathrm{Y}$, et al. Retrospective assessment of asbestos exposure - I. Case- control analysis in a study of lung cancer: efficiency of job-specific questionnaires and job exposure matrices. Int $\mathcal{F}$ Epidemiol 1993;22(suppl.2): S83-95.

24 Karjalainen A, Anttila S, Vanhala E, Vainio H. Asbestos exposure and the risk of lung cancer in a general urban population. Scand $\mathcal{f}$ Work Environ Health 1994;20:243-50.

25 Järvolm B, Larsson S, Hagberg S, Olling S, Ryd W, Torén K. Quantitative importance of asbestos as a cause of lung cancer in a Swedish industrial city: a case-referent study. Eur Respir $\mathcal{7} 1993 ; 6: 1271-5$.

26 Bethwaite PB, Pearce N, Fraser J. Cancer risks in painters: study based on the New Zealand cancer registry. Br $\mathcal{F}$ Ind Med 1990;47:742-6.

27 Keller JE Howe HL Cancer in Illinois construction workers: a study. Am $\mathcal{F}$ Ind Med 1993;24:223-30.

28 Finkelstein MM. Occupational associations with lung cancer in two Ontario cities. Am $\mathcal{F}$ Ind Med 1995;27:127-36.

29 Skov T, Weiner J, Pukkala E, Malker H, Anderson A, Lynge E. Risk for cancer of the pharynx and oral cavity among male painters in the Nordic countries. Arch Environ Health 1993;48:176-80.

30 Armstrong B, Tremblay C, Baris D, Thériault G. Lung cancer mortality and polycyclic aromatic hydrocarbons: a casecohort study of aluminum production workers in Arvida Quebec, Canada. Am $\mathcal{F}$ Epidemiol 1994;139:250-62.

31 Langard S. Prevention of lung cancer through the use of knowledge on asbestos and other work-related causes in knowledge on asbestos and other work-related causes in 20(special issue): $100-7$.

32 (sird S. Nickel-related cancer in welders. Sci Total Environ 1994;148:303-9.

33 Sjögren B, Hansen KS, Kjuus H, Persson P-G. Exposure to stainless steel welding fumes and lung cancer: a metaanalysis. Occup Environ Med 1994;51:335-6.

34 Jöckel K-H, Ahrens W, Bolm-Audorff U. Lung cancer risk and welding - preliminary results from an ongoing casecontrol study. Am $\mathcal{F}$ Ind Med 1994;25:805-12.

35 Simonato L, Vineis P, Fletcher AC. Estimates of the proportion of lung cancer attributable to occupational exposure. Carcinogenisis 1988;9:1159-65.

36 De Vos Irvine H, Lamont DW, Hole DJ, Gillis CR. Asbestos and lung cancer in Glasgow and the west of Scotland. BMf 1993;306:1503-6. 
37 Philips AN, Pocock SJ. Sample size requirements for prospective studies, with examples for coronary heart disease. $\mathcal{F}$ Clin Epidemiol 1989;42:639-48.

38 Centraal Bureau voor de Statistiek. Leefsituatie Nederlandse bevolking 1986: Kerncijfers. Den Haag: Staatsuitgeverij, 1987.

39 Dosemeci M, Cocco P, Gomez M, Stuart PA, Heineman EF. Effects on three features of a job-exposure matrix on risk estimates. Epidemiology 1994;5:124-7.

40 Bouyer J, Hémon D. Retrospective evaluation of occupational exposures in population-based case-control studies: tional exposures in population-based case-control studies: general overview with special attention to job exposure matrices. Int f Epidemiol 1993;22(suppl 2):S57-64.
41 Bouyer J, Hémon D. Studying the performance of a job exposure matrix. Int $\mathcal{f}$ Epidemiol 1993;22(suppl 2):S65-71 2 Heineman EF, Olsen JH, Pottern LM, Gomez M, Raffn E Blair A. Occupational risk factors for multiple myeloma among Danish men. Cancer Causes Control 1992;3:555-68.

43 Gomez M, Cocco P, Dosemeci M, Stuart PA. Occupational exposure to chlorinated aliphatic hydrocarbons: job exposure matrix. Am f Ind Med 1994;26:173-83.

44 Roach S. Health risks from hazardous substances at work, assessment, evaluation and control. New York: Pergamon press, 1992.

45 Lilienfeld AM, Lilienfeld DE. Foundations of epidemiology. Oxford: Oxford University Press, 1980.

\section{Occupational and Environmental Medicine - http://www.occenvmed.com}

Visitors to the world wide web can now access Occupational and Environmental Medicine either through the BMJ Publishing Group's home page (http:// www.bmjpg.com) or directly by using its individual URL (http://www.occenvmed.com). There they will find the following:

- Current contents list for the journal

- Contents lists of previous issues

- Members of the editorial board

- Subscribers' information

- Instructions for authors

- Details of reprint services.

A hotlink gives access to:

- BMJ Publishing Group home page

- British Medical Association website

- Online books catalogue

- BMJ Publishing Group books.

The web site is at a preliminary stage and there are plans to develop it into a more sophisticated site. Suggestions from visitors about features they would like to see are welcomed. They can be left via the opening page of the BMJ Publishing Group site or, alternatively, via the journal page, through "about this site". 